\title{
APPLICABILITY OF I.R. THERMOGRAPHY TO THE MEASUREMENT OF STRESS IN RABBIT
}

\author{
by N. Ludwig*, M. Gargano*, F. Luzi** C. Carenzi** and M. Verga**
}

\author{
* Istituto di Fisica Generale Applicata Facoltà di scienze Matematiche Fisiche e \\ Naturali, Università di Milano Italy \\ ** Istituto di Zootecnica - Facoltà di Medicina Veterinaria - Università di Milano - \\ Italy
}

\section{Abstract}

Among the main physiological stress indicators, the body temperature evaluation is very important and innovative because it may be monitored without directly interacting with the animal. The use of thermographic system, which is based on the detection of infrared radiation emitted by a subject, is a suitable method in order to measure temperature without any contact. A thermographic system was employed in order to single out the rabbit skin's zones most suitable for the temperature monitoring during stress challenges. 6 hybrid rabbits were observed during induced stress. The areas selected as reference are: the ocular area (globe and periocular area), the internal auricle pavilion, and a shaved area of the head. Preliminary results of this pilot study show that the thermographic technique is a suitable method for the evaluation of temperature variation on rabbit, according to the applied stressor.

\section{Introduction}

Stress induced reactions in animals include behavioural and physiological modifications aiming at coping towards the stressor. The coping strategy depends from many factors, such as the species, the individual genetics background and experience $[1 ; 2]$. The biological available responses include behaviour as well the activation of the autonomic, neuroendocrine and immune systems, which interact and allow the organism not to being overcome by pathogenic challenges [1; 3].

The behavioural coping strategy may rely on the 'fight or flight' reaction, or in adopting a freezing posture [4], depending from the individual reactive trends and from the type of stressor. Many physiological stress induced variables have been studied, such as the hormone levels related to the sympato-adrenal-medullary and to the HPA (hypothalamic-pituitary-adrenal axis) activation, respectively mainly epinephrine and norepinephrine and corticosteroids levels. As far as cardiovascular changes are concerned, stress may induce both modifications in heart rate and heart rate variability (HRV), as well vascular changes in different body's parts, including the skin $[5 ; 6 ; 7]$. Similar physiological reactions have been shown in response to alerting stimuli in the rat's tail and in the rabbit's ear [8; 9]. More recently, Vianna \& Carrive [10] have shown the same vascular changes in response to fear eliciting stimuli in the rat. In fact they found a marked drop in tail and paws temperature; on the contrary temperature of the eye, head and back increased.

The main problems in measuring body and skin temperature are associated to the difficulty in recording them without inducing other stress reactions due to handling 
by humans [11]. Thus infrared thermography may be used to remotely assess body and skin temperature, due to the radiated heat in the infrared spectrum [12], without interfering with the animal's behavioural reactions [13]. The thermographic technique in order to evaluate the stress response has been successfully applied in some research on domestic animals, although it has not yet been used in rabbits. In a preliminary study the research activity has been focused on defining reliable methods to measure rabbit's temperature variations by using an infrared camera, using a thermographic system Avio TVS 700 microbolometric uncooled LW. Zones of the rabbit skin most suitable for the temperature monitoring during stress reactions were singled out during this first testes [15]. Variations of the observed temperature are in fact limited in a range of few degrees, so emissivity coefficient can be considered constant. Furthermore, the first study allowed to detect temperature variations according to different stress responses of the same subject, although variations due to individual metabolism were not taken into account. The selected areas as reference for the detection of the temperature changes were: the internal auricle pavilion, the eye and the periocular area.

Aim of this research was to obtain temperature measurements in the aforesaid reference areas, according to the stress reaction due to different applied stressors in rabbits.

\section{Materials and Methods}

\subsection{Animals and Treatments}

The trial was assessed over a 2 months period at the experimental rabbitry of the Faculty of Veterinary Medicine at the University of Milan. Rabbits $\left(n^{\circ}=6\right)$ were housed in a single cage $(41 \times 55 \times 40 \mathrm{~cm})$ at weaning (35 days of age) and fed ad libitum using a commercial standard diet. Water was also administered ad libitum. The average environmental temperature and relative humidity during the trial were $21,2^{\circ} \mathrm{C}$ and $57,2 \%$ respectively.

Each animal has been analysed in the baseline condition (figure 1) and during the following individual tests: social stress, changing the subject's cage and placing the subject together with another one (two rabbits per cage); sudden noise stimulation; tonic immobility test, placing the rabbit on the back (figure 2).

\subsection{Thermographic Survey}

During the first phase of the study the animals have been housed in experimental cages $(60 \times 50 \times 60 \mathrm{~cm}=$ basal condition $)$ in order to optimise the thermographic shots (figure 3 ) and have been automatically monitored over $30 \mathrm{~min}$., without stressing challenges, with a frequency of 1 image per minute. During the test conditions, 2 images (50 cm the first, $20 \mathrm{~cm}$ the second one) to register the ocular area, have been recorded. Due to the presence of thick hair, we have analysed the ocular area (globe and periocular skin), the internal auricle pavilion, and a shaved area of the head (figures 4-5). In a preliminary test, different areas of rabbit skin have been studied in order to easily read the superficial temperature, as shown in the following table:

\begin{tabular}{|c|c|c|c|c|}
\hline $\begin{array}{c}\text { Rabbit A } \\
\text { Basal conditions }\end{array}$ & $\begin{array}{c}\text { Globe and } \\
\text { Pupil }\end{array}$ & $\begin{array}{c}\text { Peri-ocular } \\
\text { skin }\end{array}$ & $\begin{array}{c}\text { Internal } \\
\text { auricle } \\
\text { pavilion }\end{array}$ & $\begin{array}{c}\text { Depilated } \\
\text { head } \\
\left(\text { Average } \mathrm{T}^{\circ} \text { ) }\right.\end{array}$ \\
\hline
\end{tabular}


http://dx.doi.org/10.21611/qirt.2006.055

\begin{tabular}{|c|c|c|c|c|}
\hline $\begin{array}{c}\text { Average } \\
\text { temperature } \\
\pm \text { standard error }\end{array}$ & $35,6 \pm 0,5$ & $33,5 \pm 0,85$ & $36.5 \pm 0.9$ & $33.6 \pm 0.6$ \\
\hline
\end{tabular}

Eyes emissivity has been supposed equal to the water emissivity. The skin and fur emissivity has been supposed equal to 0.97 in the $8-14 \mu \mathrm{m}$ wavelenght range [16].

\section{Result and Discussion}

In this pilot study the results showed that the best area to check the body temperature in rabbits could be the eye compared to the internal ear pavillon, due to the different ear positions during the thermographic shots. Anyway, we tried to analyse the temperature of the depilated area of the head: also in this position, the main problem was the presence of the fur during the subsequent tests. The periocular area was no more considered due to the difficulty to distinguish it from the eye.

In figure 6 the temperature/time evolution for six rabbits in the first experiment is reported. The data show that temperaure is quite costant after about five minutes, time interval in wich rabbits could be affected by the adaptation period to the new cage. The temperature difference between eye and ear is higher than the statistical error (standard deviation) of the data of the six rabbit.

The best site to check an eventual stress condition was the ear skin, due the vasoconstriction process, as showed also by Vianna and Carrive [10]. These authors used the infrared thermography to check eventual changes in cutaneous temperature during a conditioned fear response to context in rats. A marked drop in tail and paw temperature was observed in fear conditioned rats. In contrast, temperature of the eye, head and back increased. This study shows that fear evokes a cutaneous vasoconstriction in the tail and paws. It could be a preparatory response to a possible fight and flight to reduce blood loss in the most exposed parts of the rat's body in case of iniury.

Franzini et al. [14] reported that there is a direct action of emotional stress on effector controllers for respiration and vasomotion in rabbit. Furthermore, in 1950, Grant [17] already had studied the effect of physical restraint on hypothermia in rabbits. Also in our trial, rabbits showed a drop in ear average temperature between the basal and stress conditions (figures 7 and 8 ). In particular in the basal condition the different temperature

$$
\Delta T=\bar{T}_{e a r}-\bar{T}_{\text {eye }}
$$

over the six rabbits is positive while in the stress condition $\Delta T$ is negative for four rabbits. On the contrary, the eye average temperature during the stress resulted the same and sometimes increased compared to the basal temperature (figure 7).

\section{Conclusion}

The results of this pilot study show that the thermographic technique is a suitable method for the evaluation of temperature variation in rabbit, revealing the temperature variations according to different applied stressors. The variations related to the physiological changes during the stress reaction are evidenced in the ear skin, where a vasoconstriction process occurs. Further research is needed in order to 
obtain more results, measuring also the periocular area temperature and increasing the number of animal, in order to standardise the methodology.

\section{Acknowledgements}

The Authors wish to thank for the kind collaboration:

dr Marino Campagnol, dr Eugenio Heinzl, dr Roberta Pasi, dr Daniela Zucca and dr Alessandra Cocilovo (Central Rabbitry Responsible - Vet. Med. Faculty University of Milan). 
http://dx.doi.org/10.21611/qirt.2006.055

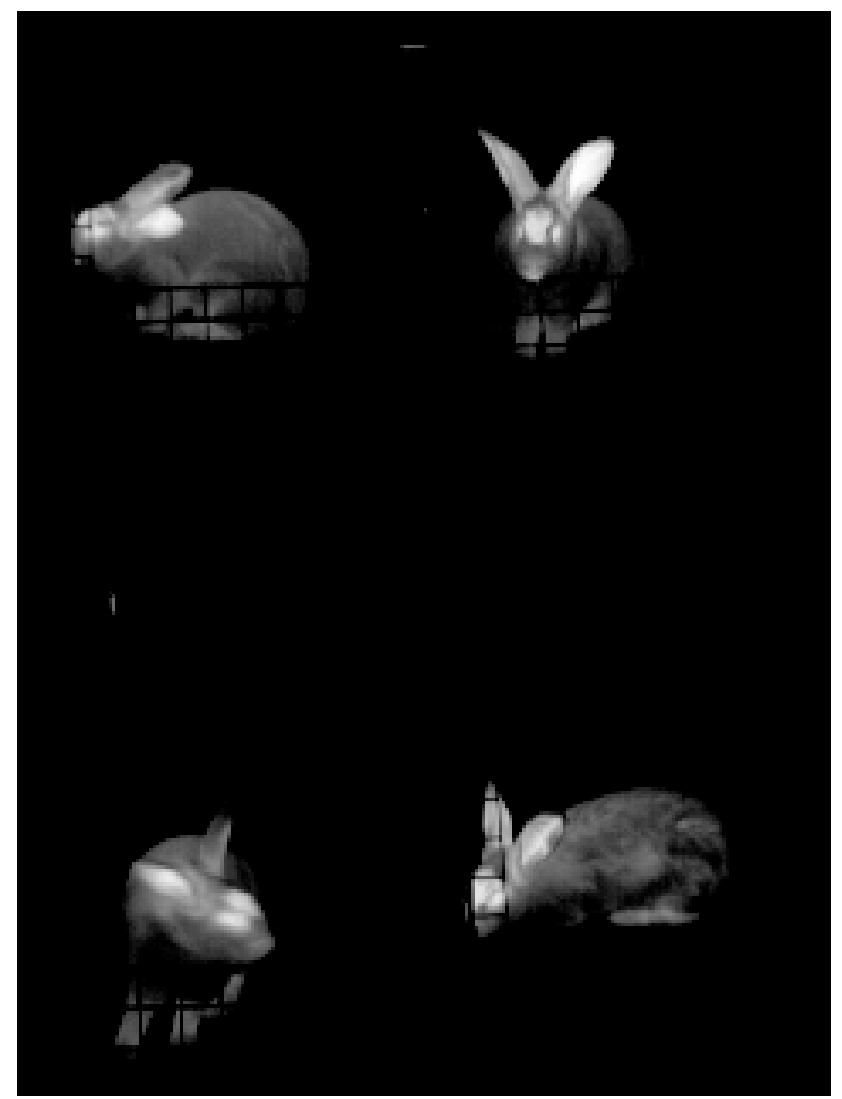

Fig. 1. Rabbits in basal condition, animals are in four separated cages.

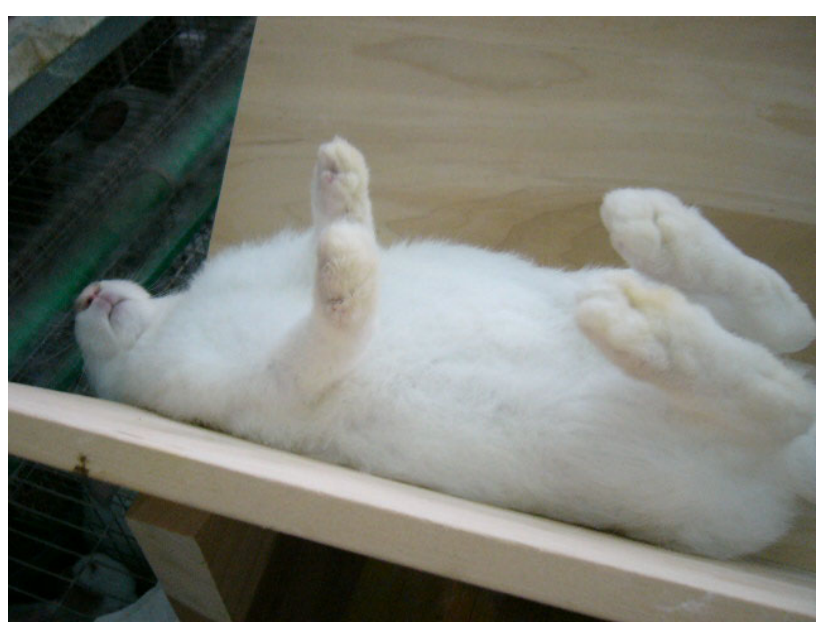

Fig. 2 Tonic immobility test 
http://dx.doi.org/10.21611/qirt.2006.055

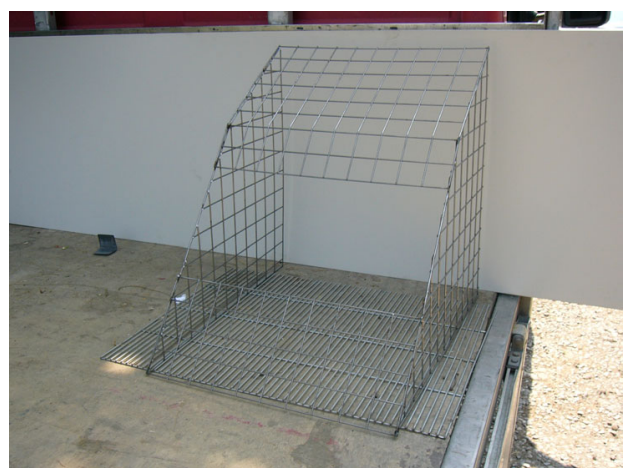

Fig. 3 Test cage

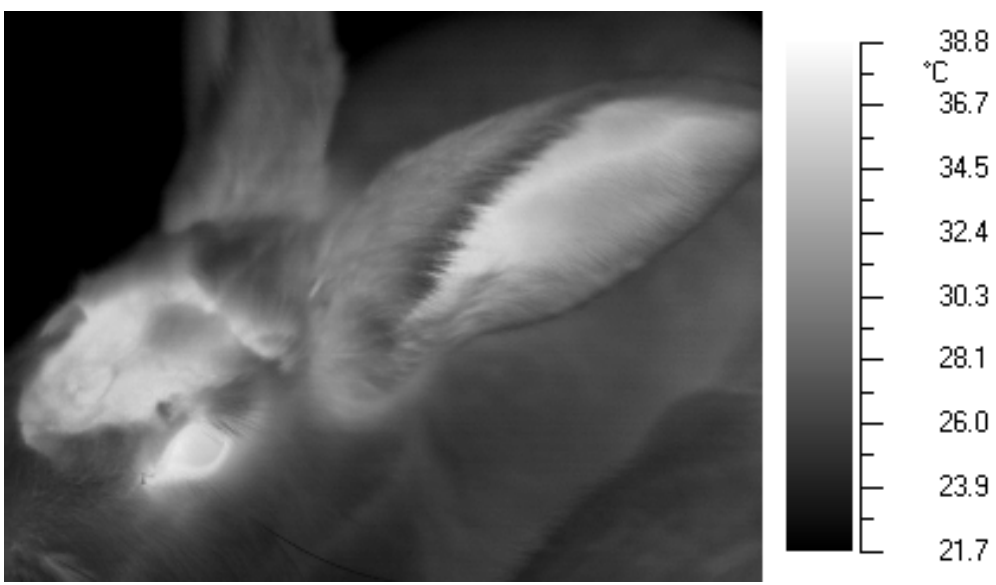

Fig. 4. Temperature distribution of a rabbit under laboratory condition (eye, ear and shaved skin) under laboratory condition

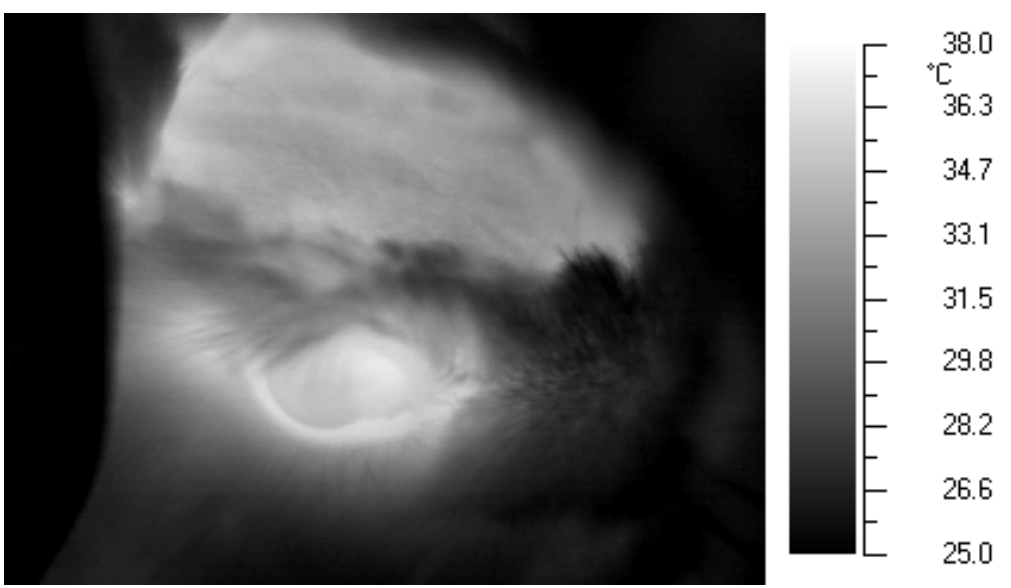

Fig. 5. Detail of temperature distribution of a rabbit under laboratory condition (eye and shaved skin) 


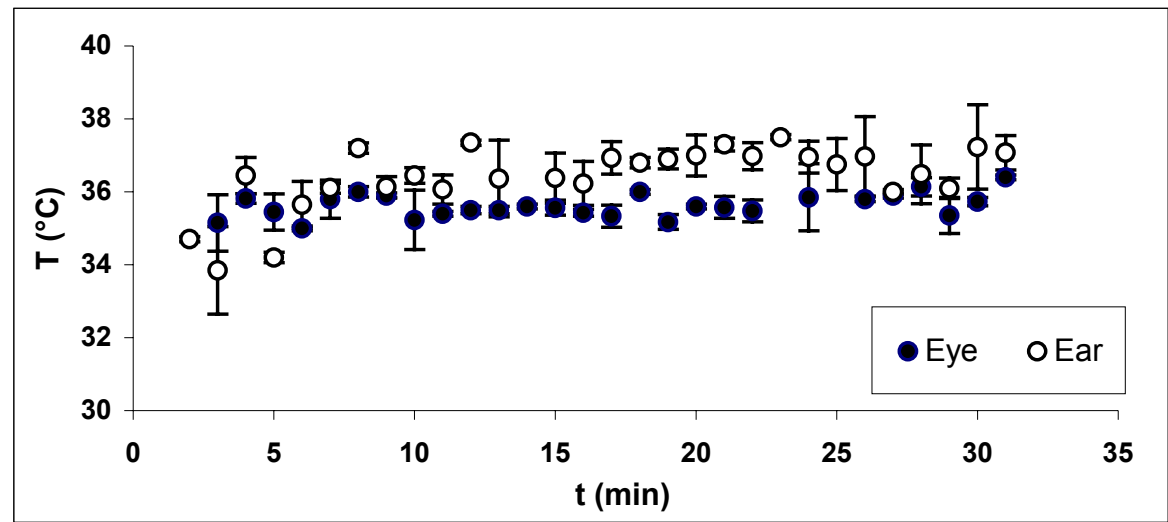

Fig. 6 Evolution of eye and ear temperature during basal condition, each datum is the average over the six rabbits.

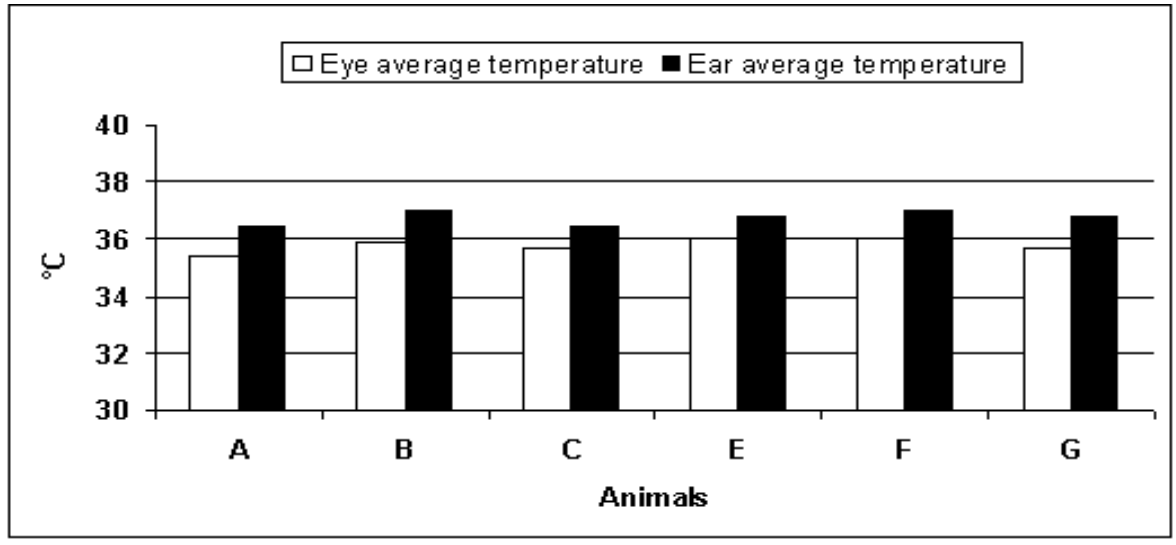

Fig. 7 Eye and ear average temperature in basal condition.

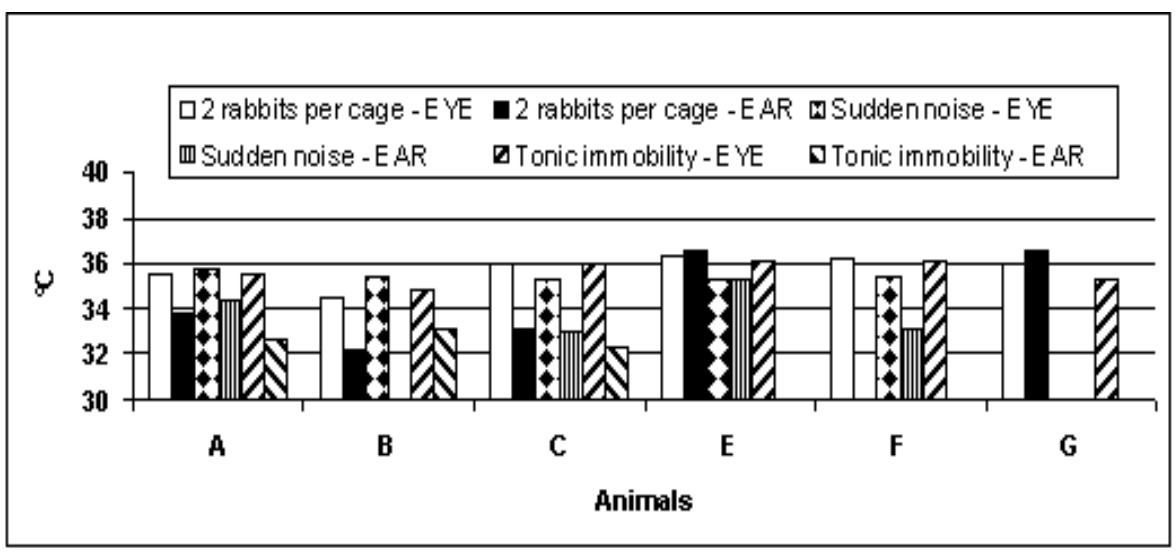

Fig. 8 Eye and ear mean temperature divided per type of stressor. 


\section{REFERENCES}

[1] G.P. Moberg and J.A. Mench. The biology of animal stress: basic principles and implications for animal welfare. (2000) CABI Publishing; Wallingford; UK.

[2] J.P. Henry and P.M. Stephens. Stress, health and the social environment. A sociobiologic approach to medicine. (1977) Springer-Verlag new York Inc.

[3] Biondi, 1997. Mente, cervello e sistema immunitario. (1997) McGraw-Hill Libri Italia srl.

[4] R.J. Blanchard, K.J. and D.C. Blanchard. Defensive behaviors of laboratory and wild Rattus Norvegicus. J. Comp. Psychol., 100 (1986) 101-107.

[5] W. W. Blessing. Lower brainstem pathways regulating sympathetically mediated changes in cutaneous blood flow. Cellular and Molecular Neurobiology, 23, 4/5 (2003) 527-538.

[6] B.P. Godsil, J.J. Quinn and M.S. Fanselow. Body temperature as a conditional response measure for Pavlovian fear conditioning. Learn. Mem., 7 (2000) 353356.

[7] P. Walker and P. Carrive. Role of ventrolateral periaqueductal gray neurons in the behavioural and cardiovascular responses to contextual conditioned fear and poststress recovery. Neuroscience, 116 (2003) 897-912.

[8] W. W. Blessing and B. Seaman. 5-Hydroxytryptamine $2 A$ receptors regulate sympathetic nerves constricting the cutaneous vascular bed in rabbits and rats. Neuroscience, 117 (2003) 939-948.

[9] Y. H. Yu \& and W. Blessing. Neurons in amygdale mediate ear pinna vasoconstriction elicited by unconditioned salient stimuli in conscious rabbits. Autonomic Neuroscience: Basic and Clinical, 87 (2001) 236-242.

[10] D.M.L. Vianna and P. Carrive. Changes in cutaneous and body temperature during and after conditioned fear to context in the rat. European Journal of Neuroscience, 21 (2005) 2505-2512.

[11] R.Berz, Regulation Thermography-a survey, QIRT 4-Medical (1998) 18-25

[12] F. Jones and P. Plassmann. Digital infrared thermal imaging of human skin. IEEE Eng. Med. Biol. Mag., 21 (2002) 41-48.

[13] G. Kastberger and R. Stachl. Infrared imaging technology and biological applications. Behav. Res. Meth. Instrum. Comput., 35 (2003) 429-439.

[14] C. Franzini, P. Lenzi and T. Cianci. Interactions between temperature regulation and emotional arousal in the rabbit. Exp. Brain Res., 43 (1981) 8792.

[15] F. Luzi, N. Ludwig, M. Gargano, C. Carenzi , M. Verga. Valutazione dello stress nella specie cunicola per mezzo di termografia ad infrarosso.Atti delle Giornate di Coniglicoltura Asic 2005 pag. 101

[16] D. Pajani, Mesure par thermographie infrarouge, ADD.Ed (1989) ISBN 29504171-0-8

[17] R. Grant. Emotional hypotermia in rabbits. An. J. Physiol., 160 (1950) 285-290. 